\title{
PENGARUH PENGETAHUAN ORANG TUA TENTANG PAUD TERHADAP KEIKUTSERTAAN ANAK PADA PENDIDIKAN NONFORMAL DI DESA TEGAL KERTHA DENPASAR 2019
}

\author{
Gusti Ayu Martha Winingsih ${ }^{1}$ \\ ${ }^{1}$ Politeknik Kesehatan Kartini Bali \\ Email : gekmartha@gmail.com
}

\begin{abstract}
ABSTRAK
Pendidikan pada usia dini masih di pandang sebelah mata oleh masyarakat, kenyataan bahwa masih banyak anak usia dini yang belum mendapatkan pelayanan pendidikan. Hal itu disebabkan antara lain kesadaran masyarakat akan pentingnya pendidikan bagi anak usia dini masih sangat rendah. Ada beberapa faktor yang menjadikan penyebab seperti : ketidaktahuan, kemiskinan, kurang berpendidikan, gagasan orang tua tentang perkembangan anak yang masih sangat tradisional, kurang mau berubah, masih sangat konkret dalam berpikir, motivasi yang rendah karena kebutuhan yang masih sangat mendasar, serta masih sangat dipengaruhi oleh budaya setempat yang sempit. Tujuan penelitian untuk mengetahui pengaruh pengetahuan orang tua tentang PAUD terhadap keikutsertaan anak usia dini pada pendidikan nonformal, Penelitian ini bersifat deskriptif korelatif dengan pendekatan cross sectional. Penelitian dilaksanakan di Banjar Panca Kertha Desa Tegal Kertha Denpasar Barat dilaksanakan pada bulan Juli 2019 - Agustus 2019. Populasinya adalah seluruh Orang tua yang mempunyai anak usia 2-3 tahun di Banjar Panca Kertha, Desa Tegal Kertha Denpasar Barat yang berjumlah 40 orang. Pengambilan sampel dengan total sampling. Hasil yang di dapat hampir setengahnya $(27,5 \%)$ orang tua memiliki pengetahuan yang kurang mengenai pendidikan anak usia dini. Sebagian besar $(67,5 \%)$ orang tua tidak mengikutsertakan anaknya pada pendidikan anak usia dini. Ada pengaruh yang sangat signifikan antara pengetahuan orang tua tentang pendidikan anak usia dini terhadap keikutsertaan anak usia 2-3 tahun pada pendidikan anak usia dini nonformal di Banjar Panca kertha Desa Tegal Kertha Denpasar.
\end{abstract}

Kata Kunci : Pengetahuan orang tua, PAUD, Keikutsertaan, Pendidikan anak Usia Dini

\section{ABSTRACT}

Education at an early age is still underestimated by the community, the fact that there are still many early childhood who have not received educational services. That was caused by among others public awareness of the importance of education for early childhood is still very low. There are several factors that make the cause such as: ignorance, poverty, lack of education, parental ideas about the development of children who are still very traditional, less willing to change, are still very concrete in thinking, low motivation because the needs are still very basic, and are still very influenced by narrow local culture. The purpose of this study was to determine the effect of parents' knowledge about PAUD on early childhood participation in non-formal education. This research is descriptive correlative with cross sectional approach. The study was conducted in Banjar Panca Kertha, Tegal Kertha Village, West Denpasar, conducted in July 2019 - August 2019. The population was all parents who had children aged 2-3 years in Banjar Panca Kertha, Tegal Kertha Village, West Denpasar, amounting to 40 people. Sampling with total sampling. The results obtained almost half (27.5\%) parents have less knowledge about early childhood education. Most (67.5\%) parents did not include their children in early childhood education. There is a very significant influence between parental knowledge about early childhood education on the participation of children aged 2-3 years in non-formal early childhood education in Banjar Panca kertha, Tegal Kertha Village, Denpasar.

Keywords: Parental knowledge, PAUD, Participation, Early Childhood Education 
Jurnal Kesehatan Karya Husada, No 8 Vol 2 Tahun 2020

PISSN 2337649X/EISSN 2655-8874

Gusti Ayu Martha Winingsih “Pengaruh Pengetahuan Orang Tua Tentang PAUD Terhadap Keikutsertaan Anak Pada Pendidikan Nonformal di Desa Kertha Denpasar 2019" (hal 76-83)

\section{PENDAHULUAN}

Periode sejak anak lahir hingga kurang lebih usia 4 tahun dipercaya sebagai periode keemasan golden age di mana anak mengalami perkembangan yang pesat terutama kecerdasan otak. Perkembangan jaman tentunya menuntut adanya perubahan termasuk dalam mendidik anak. Orang tua sekarang mulai merasakan perlunya pendidikan anak usia dini di sekolah bahkan ada yang dimulai dari usia 18 bulan. Periode ini adalah tahun - tahun berharga bagi seorang anak untuk mengenali berbagai macam fakta di lingkungannya sebagai stimulans terhadap perkembangan kepribadian, psikomotor, kognitif maupun sosialnya (Muthia dan Diana, 2010).

Hasil penelitian Asmani 2009 membuktikan bahwa pemberian pendidikan sejak dini akan mempengaruhi perkembangan otak anak, kesehatan anak, kesiapan anak bersekolah, kehidupan sosial dan ekonomi yang lebih baik di masa selanjutnya, jika dibandingkan dengan anak - anak yang kurang terdidik pada usia dini. Kenyataan bahwa masih banyak anak usia dini yang belum mendapatkan pelayanan pendidikan. Hal itu disebabkan antara lain kesadaran masyarakat akan pentingnya pendidikan bagi anak usia dini masih sangat rendah.

Ada beberapa faktor yang menjadikan penyebab masih rendahnya kesadaran masyarakat di bidang pendidikan anak usia dini seperti : ketidaktahuan, kemiskinan, kurang berpendidikan, gagasan orang tua tentang perkembangan anak yang masih sangat tradisional, kurang mau berubah, masih sangat konkret dalam berpikir, motivasi yang rendah karena kebutuhan yang masih sangat mendasar, serta masih sangat dipengaruhi oleh budaya setempat yang sempit (Sumarno dan Ali, 2011)

Data Dinas Pendidikan dan Kebudayan Provinsi Bali tahun 2011 menunjukkan jumlah anak usia 2 - 3 tahun sampai sebanyak 1583 anak. jumlah PAUD Nonformal yang ada di Kabupaten Buleleng sebanyak 211 anak, Kabupaten Jembrana 152, Kabupaten Tabanan sebanyak 234 anak, Badung Page 77 
Jurnal Kesehatan Karya Husada, No 8 Vol 2 Tahun 2020

PISSN 2337649X/EISSN 2655-8874

Gusti Ayu Martha Winingsih "Pengaruh Pengetahuan Orang Tua Tentang PAUD Terhadap Keikutsertaan Anak Pada Pendidikan Nonformal di Desa Kertha Denpasar 2019" (hal 76-83)

227 anak, Kabupaten Gianyar 150 anak, Kabupaten Klungkung sebanyak 90 anak, Bangli 71 anak, Kabupaten Karangasem sebanyak 127 dan Kabupaten Denpasar sebanyak 32. Dari Banjar yang ada di Kecamatan Denpasar Barat, Banjar Panca Kertha merupakan Banjar dengan jumlah anak usia 2 - 3 tahun terbanyak yaitu sebesar 40 anak.

Berdasarkan studi pendahuluan dengan wawancara kepada orang tua di dapatkan dari 10 orang tua yang di wawancara 8 orang tua $(80 \%)$ mengatakan Pendidikan usia dini tidak penting karena anak masih kecil dan buang-buang uang, sedangkan 2 orang tua $(20 \%)$ pendidikan usia dini sangat penting karena banyak manfaatnya salah satunya bisa bersosialisasi sejak dini.

\section{METODE PENELITIAN}

Penelitian ini bersifat deskriptif korelatif, yaitu penelitian yang dilakukan untuk melihat hubungan antara variabel satu dengan variabel yang lain (Notoatmodjo, 2010).
Pendekatan yang digunakan adalah Cross Sectional yaitu suatu penelitian untuk mempelajari hubungan antara variabel bebas dengan terikat dengan melakukan penelitian dalam waktu yang bersamaan(Arikunto,

2010).

Penelitian ini dilaksanakan di Banjar Panca Kertha Desa Tegal Kertha Denpasar Barat, dilaksanakan pada bulan Juli 2019 - Agustus 2019. Populasi dalam penelitian ini adalah seluruh Orang tua yang mempunyai anak usia 2-3 tahun di Banjar Panca Kertha, Desa Tegal Kertha Denpasar Barat pada Bulan Januari - April 2019 yang berjumlah 40 orang tua yang mempunyai anak usia 2-3 tahun.

Teknik pengambilan sampel dalam penelitian ini adalah total sampling. Total sampling adalah teknik pengambilan sampel dimana jumlah sampel sama dengan populasi

(Sugiyono, 2012). Alasan mengambil total sampling karena menurut (Sugiyono, 2012) jumlah populasi yang kurang dari 100 seluruh populasi dijadikan sampel penelitian semuanya. 
Jurnal Kesehatan Karya Husada, No 8 Vol 2 Tahun 2020

PISSN 2337649X/EISSN 2655-8874

Gusti Ayu Martha Winingsih "Pengaruh Pengetahuan Orang Tua Tentang PAUD Terhadap Keikutsertaan Anak

Pada Pendidikan Nonformal di Desa Kertha Denpasar 2019” (hal 76-83)

HASIL DAN PEMBAHASAN

Tabel 1. Distribusi Frekuensi Pengetahuan Orang tua Tentang Pendidikan PAUD di Banjar Panca Kertha Desa Tegal Kertha Denpasar Barat Tahun 2019

\begin{tabular}{|c|c|c|c|}
\hline No. & Pengetahuan & $\begin{array}{c}\text { Frekuensi } \\
\text { (f) }\end{array}$ & $\begin{array}{c}\text { Persentase } \\
\text { (\%) }\end{array}$ \\
\hline 1 & Baik & 8 & 20 \\
\hline 2. & Cukup & 11 & 27.5 \\
\hline 3. & Kurang & 21 & 52.5 \\
\hline & Total & 40 & 100 \\
\hline
\end{tabular}

Sumber: Data Primer Penelitian Tahun 2019

Hasil penelitian terhadap 40 responden yaitu 8 responden $(20 \%)$ memiliki pengetahuan baik, 11 responden $\quad(27.5 \%) \quad$ memiliki pengetahuan cukup, dan 21 responden $(52.5 \%)$ memiliki pengetahuan kurang. hasil penelitian ini di menunjukkan bahwa sebagian besar responden 52,5 $\%$ memiliki pengetahuan kurang.

Hasil penelitian ini sesuai dengan pendapat (Nothoadmojo, 2010) bahwa pengetahuan merupakan domain yang sangat penting dalam membentuk tindakan seseorang. Hal ini juga sejalan dengan penelitian (Andini, 2013) yang mana pada penelitian tersebut menyebutkan bahwa kurangnya pengetahuan orang tua tentang pendidikan anak usia dini menyebabkan masih banyaknya orang tua yang tidak mengikutsertakan anaknya pada pendidikan anak usia dini.

Tabel 2. Distribusi Frekuensi Keikutsertaan Anak pada Pendidikan Anak Usia Dini Nonformal di Banjar Panca kertha Desa Tegal Kertha Denpasar Barat Tahun 2019

\begin{tabular}{|c|l|c|c|}
\hline No & Keikutsertaan & $\begin{array}{c}\text { Frekuensi } \\
\text { (f) }\end{array}$ & $\begin{array}{c}\text { Persentase } \\
\text { (\%) }\end{array}$ \\
\hline 1. & Ikut & 11 & 27.5 \\
\hline 2. & Tidak Ikut & 29 & 67.5 \\
\hline & Jumlah & 40 & 100 \\
\hline
\end{tabular}

Sumber: Data Primer Penelitian tahun 2019

Hasil penelitian terhadap 40 responden, ada 29 responden $(67.5 \%)$ responden tidak mengikutsertakan anaknya pada PAUD dan ada 11 responden (27.5\%) responden mengikutsertakan anaknya pada PAUD . Hasil penelitian ini menunjukkan bahwa orang tua tidak mengikutsertakan anaknya pada 
Jurnal Kesehatan Karya Husada, No 8 Vol 2 Tahun 2020

PISSN 2337649X/EISSN 2655-8874

Gusti Ayu Martha Winingsih "Pengaruh Pengetahuan Orang Tua Tentang PAUD Terhadap Keikutsertaan Anak

Pada Pendidikan Nonformal di Desa Kertha Denpasar 2019” (hal 76-83)

pendidikan usia dini nonformal sebesar $67,5 \%$.

Berdasarkan hasil penelitian, sebagian besar orang tua menyampaikan alasan bahwa orang tua tidak mengikutsertakan anaknya pada pendidikan anak usia dini karena usianya yang masih terlalu kecil sehingga orang tua beranggapan belum saatnya untuk memasukkan anak mereka pada pendidikan anak usia dini. Hal ini sangat wajar mengingat bahwa pemahaman masyarakat terhadap pentingnya pendidikan anak usia dini masih sangat rendah serta pada umumnya mereka berpandangan bahwa pendidikan identik dengan sekolah, sehingga bagi anak usia dini pendidikan dipandang belum perlu (Listiana Lia, 2011).

Tabel 3. Pengaruh pengetahuan orang tua tentang PAUD terhadap keikutsertaan anak pada Pendidikan Nonformal di Banjar Panca Kertha Desa Tegal Kertha Denpasar Tahun

2019

\begin{tabular}{|c|c|c|c|c|}
\hline \multirow{2}{*}{$\begin{array}{c}\text { Pengetahuan } \\
\text { Orang tua } \\
\text { Tentang PAUD }\end{array}$} & \multicolumn{2}{|c|}{$\begin{array}{c}\text { Kelkutsertaan Anak } \\
\text { Usia 2-3 Tahun pada } \\
\text { PAUD }\end{array}$} & \multirow{2}{*}{ value } & \multirow[t]{2}{*}{ OR } \\
\hline & $\begin{array}{c}\text { Ikut } \\
\text { PAUD }\end{array}$ & $\begin{array}{c}\text { Tidak ikut } \\
\text { PAUD }\end{array}$ & & \\
\hline Baik & $4(100 \%)$ & 0 & & \\
\hline Cukup & $5(55,5 \%)$ & $4(44,5 \%)$ & 0,000 & 45,222 \\
\hline Kurang & $2(11,8 \%)$ & $15(88,2 \%)$ & & \\
\hline Total & $\mathrm{II}(36,6 \%)$ & $19(63,4 \%)$ & & \\
\hline
\end{tabular}

Sumber: Data Primer Penelitian Tahun 2019

Pada Tabel 3 menunjukkan bahwa orang tua yang mengikutsertakan anaknya pada PAUD sebagian besar $(55,5 \%)$ orang tua mempunyai pengetahuan yang cukup tentang PAUD dan orang tua yang tidak mengikutsertakan anaknya pada PAUD sebesar $88,2 \%$ orang tua mempunyai pengetahuan kurang tentang PAUD. Uji statistic yang digunakan adalah Chi Square karena variabel yang dianalisa adalah kategorik dengan kategorik(Stang, 2017). Berdasarkan hasil Uji Chi Square dengan tabel 2x2 dan tidak terdapat nilai ekspetasi (E) $<5$, maka digunakan Continuity Correction (a) dan dilakukan dengan tingkat kepercayaan 99\% $(\alpha=0,01)$. Hasil analisa data diperoleh $\rho$ value $=$ 0,000 ( $\rho$ value $<0,01$ ) sehingga dapat

Page 80 
Jurnal Kesehatan Karya Husada, No 8 Vol 2 Tahun 2020

PISSN 2337649X/EISSN 2655-8874

Gusti Ayu Martha Winingsih “Pengaruh Pengetahuan Orang Tua Tentang PAUD Terhadap Keikutsertaan Anak Pada Pendidikan Nonformal di Desa Kertha Denpasar 2019" (hal 76-83)

disimpulkan dengan $\alpha=1 \%$, ada pengaruh yang sangat signifikan antara pengetahuan orang tua tentang pendidikan anak usia dini terhadap keikutsertakan anak usia 2-3 tahun pada Pendidikan Anak .

Bahwa dari 40 responden yang berpengetahuan kurang, ada $88,2 \%$ responden tidak mengikutsertakan anaknya pada pendidikan anak usia dini. Hasil penelitian ini sesuai dengan pendapat (Nothoadmojo, 2010) yang menyatakan bahwa pengetahuan akan menimbulkan kesadaran dan akhirnya menyebabkan orang berperilaku sesuai dengan pengetahuan yang dimilikinya. Nilai $\mathrm{OR}=45,222$ yang berarti bahwa setiap orang tua yang mempunyai pengetahuan kurang mengenai pendidikan anak usia dini mempunyai peluang 45 kali untuk mengikutsertakan anaknya pada pendidikan anak usia dini. (Asmani dan Jamal Makmur, 2009) yang menyatakan bahwa faktor predisposisi terbentuknya perilaku seseorang adalah pengetahuan.

Hasil penelitian ini sesuai dengan teori tersebut, bahwa orang tua yang berpengetahuan cukup mengenai pendidikan anak usia dini lebih banyak mengikutsertakan anaknya pada pendidikan anak usia dini dibandingkan orang tua yang berpengetahuan kurang mengenai pendidikan anak usia dini.

Pengetahuan yang kurang terhadap pendidikan anak usia dini menyebabkan orang tua kurang berpartisipasi dalam pendidikan anak usia dini. Masih banyaknya jumlah responden yang tidak mengikutsertakan anaknya pada pendidikan anak usia dini dalam penelitian ini menunjukkan bahwa motivasi orang tua untuk mengikutsertakan anaknya dalam program pendidikan anak usia dini masih kurang.

Hal ini sesuai dengan penelitian (Abdullah, 2015), bahwa banyak faktor yang mempengaruhi motivasi orang tua untuk mengikutsertakan anaknya dalam program PAUD antara lain tingkat pengetahuan, kepribadian, sikap, citacita, lingkungan, dan kemampuan ekonomi. Pengetahuan orang tua yang kurang tentang pendidikan anak usia dini dapat ditingkatkan dengan menambah informasi tentang Page 81 | 
Jurnal Kesehatan Karya Husada, No 8 Vol 2 Tahun 2020

PISSN 2337649X/EISSN 2655-8874

Gusti Ayu Martha Winingsih "Pengaruh Pengetahuan Orang Tua Tentang PAUD Terhadap Keikutsertaan Anak Pada Pendidikan Nonformal di Desa Kertha Denpasar 2019" (hal 76-83)

pendidikan anak usia dini (Ernawati, 2014)

\section{SIMPULAN DAN SARAN}

Orang tua memiliki pengetahuan yang kurang mengenai pendidikan anak usia dini sebesar $27,5 \%$. Orang tua tidak mengikutsertakan anaknya pada pendidikan anak usia dini sebesar $67,5 \%$. Ada pengaruh yang sangat signifikan antara pengetahuan orang tua tentang pendidikan anak usia dini terhadap keikutsertaan anak usia 2-3 tahun pada pendidikan anak usia dini nonformal di Banjar Panca kertha Desa Tegal Kertha Denpasar.

\section{DAFTAR PUSTAKA}

Abdullah. (2015). Hubungan pola asuh orang tua dengan konsep diri anak usia sekolah.

Muhammadiyah Malang Jurnal. Malang: Program Studi Magister Universitas.

Andini. (2013).

Faktor-faktor

yang Mempengaruhi Persepsi dan Partisipasi Orang tua dalam
Pendidikan Anak Usia Dini di Keluarga. Universitas Sebelas Maret Surakarta.

Arikunto. (2010). Prosedur Penelitian

Pendekatan Praktik. Rineka Cipta, Jakarta.

Asmani dan Jamal Makmur.

(2009). Manajemen Strategis

Pendidikan Anak Usia Dini. DIVA

Press, Jakarta. Ernawati. (2014).

Pengaruh keikutsertaan pendidikan

di PAUD terhadap

perkembangan personal sosial

anak

3-5 tahun. STIKES Karya

Husada Semarang.

Listiana Lia. (2011). Motivasi Orang tua dalam Mengikutsertakan Anaknya pada Pendidikan Anak Usia Dini di Kecamatan Tirto Kabupaten Pekalongan. STIKES Muhammadiyah Pekajangan.

Muthia dan Diana. (2010). Psikologi Bermain Anak Usia Dini. Kencana, Jakarta.

Nothoadmojo. (2010). Metodologi

Penelitian Kesehatan. Jakarta:

Rineka

Cipta. 
Jurnal Kesehatan Karya Husada, No 8 Vol 2 Tahun 2020

PISSN 2337649X/EISSN 2655-8874

Gusti Ayu Martha Winingsih "Pengaruh Pengetahuan Orang Tua Tentang PAUD Terhadap Keikutsertaan Anak

Pada Pendidikan Nonformal di Desa Kertha Denpasar 2019" (hal 76-83)

Stang. (2017). Cara Praktis Penentuan

Uji Statistik Dalam Penelitian

Kesehatan

dan

Kedoktera

n. Jakarta: Mitra Wacana

Media.

Sugiyono. (2012). Statistika

untuk Penelitian. Bandung:

Alfabeta. Sumarno dan Ali.

(2011). Perkembangan Peserta

Didik di PAUD.

http://www.scribd.com. 